Mariana Masera

Seminario de Poética, IIFL, UNAM

\title{
El Nuevo Mundo y el Viejo Mundo en la canción tradicional mexicana: del villancico a la copla
}

En la Nueva España existió una sociedad multicultural, formada principalmente por indígenas, africanos y europeos, que dejó su huella en las diferentes manifestaciones artísticas cultas y populares, como afirma Alfonso Reyes:

En sólo el primer siglo de colonia, consta ya por varios testimonios la elaboración de una sensibilidad y un modo de ser novohispanos distintos de los peninsulares, efecto de ambiente natural y social sobre los estratos de las tres clases mexicanas: criollos, mestizos e indios. (Reyes 1992, 35)

La cultura novohispana se constituye de una diversidad de confluencias entre la cultura que era la de los vencedores y la cultura de los vencidos. Cada una de estas dos tendencias tiene su propio discurso, de acuerdo con la teoría del Iceberg propuesta por Robles Cahero: el de la élite es aquel que comprende lo "público y lo consciente", el que es evidente, y se conserva principalmente via escrita; y el de la cultura subalterna, es el discurso de lo doméstico y lo incosnciente, el que es latente y profundo, que se transmite vía oral principalmente. ${ }^{1}$

${ }^{1}$ Cf. Robles Cahero 1984: pp. 26-27. 
Desde el aspecto literario, las formas líricas breves más difundidas durante el virreinato fueron el villancico (siglos XVI y xvII) y posteriormente la copla suelta (siglos xvIII al xx). Ambas estructuras poéticas, por su brevedad y relativa sencillez, se asociaron a la cultura de plaza y a la tradición oral. Cabe agregar, sin embargo, que el villancico en la Nueva España es un género que fue impuesto por la iglesia, es decir, nos llega ya un texto que ha pasado por el tamiz de los religiosos y que ha sido regularizado; pero que, sin embargo, en sus estribillos predomina el tono tradicional y en algunos netamente, son tomados la tradición oral española. En este trabajo intento mostrar algunos rasgos poéticos de los textos que prefiguran y constituyen la "otra cultura" novohispana a partir de ejemplos que han quedado registrado. ${ }^{2}$

En la primera parte, analizaré villancicos del siglo xvi y del siglo xvir donde se puede observar una evolución poética. En tanto que en el primer tercio del xvi hallamos textos muy apegados al cancionero popular español, en el xvin, a pesar de conservar una forma peninsular, en el contenido se imprime la huella novohispana.

En la segunda parte, estudio las coplas - aquí me refiero generalmente a la cuarteta sea o no octosilábica - de "El chuchumbé", un son prohibido y perseguido por la Inquisición durante más de cuarenta años. Además, es un texto característico

2 Aquí entiendo popular en su más amplio sentido, tanto en el modo de creación como en la recepción. Algunas características distintivas son: el texto "es creado y cantado principalmente en las áreas marginadas rurales y urbanas. Segundo, es una poesía que ofrece variantes, donde el punto de vista de la comunidad se impone, la mayor de las veces, sobre el punto de vista individual tanto en el proceso de creación como en el de recreación. Tercero, la poesía popular es una poesía que se crea y trasmite principalmente de manera oral. Cuarto y último, los recursos poéticos son limitados y conocidos por todos, tanto creadores como escuchas. Aún más, no existe una única poesía tradicional ahistórica, por el contrario, han existido a lo largo del tiempo y existen distintas poesías tradicionales circunscritas a ciertas regiones y períodos" (Masera 2000: p. 141). También he incluido en mi análisis textos popularizantes, que son aquellos textos de factura más bien culta que imitan al tipo tradicional. 
del siglo xvin y representa la consolidación de una cultura popular novohispana. ${ }^{3}$

"El chuchumbé" tiene una estructura moderna de canción, compuesta por coplas "más o menos independientes unas de otras, que se asocian muchas veces al azar, que se suelen cantar con melodías de canciones diferentes y que, aun cuando sólo pertenecen a una canción determinada, no quedan sujetas a un orden definido" (Frenk 1975: p. xvii).

\section{El Villancico}

En la Península Ibérica es larga la tradición del género. De acuerdo con Antonio Sánchez Romeralo (1969: 42): "Villancico equilvadría entonces a canción popular, designaría a las canciones de la tradición popular, cantadas por los villanos", y el autor añade que

por extensión o derivación, llegarían a designar una canción compuesta según determinada forma estrófica. Por los cancioneros del siglo xv y comienzos del xvi vemos, en efecto, que reciben ahora ese nombre canciones no populares, sino cultas de fraseología y tema cortés, y es obvio que el nombre de villancico tiene una connotación formal, estrófica.

En cuanto a la temática "era, pues, en su origen, cualquier canto o diálogo pastoril, o más en general rusticanos, con toda la amplitud de su inicial sinónimo 'villanesca' [...]siéndole indiferente el contenido profano o sacro" (Méndez Plancarte 1952: xii). ${ }^{4} \mathrm{El}$ nombre de villancico se extendió a todas las demás letras que se cantaban en los templos (Méndez Plancarte 1952: p. xiii).

${ }^{3}$ Aquí defino la copla como el "complejo temático-formal que tiene el carácter de unidad poética mínima" (Magis 1969: p. 27).

4 "Una composición poética popular, con estribillo, y especialmente la de asunto religioso y que se canta en las Iglesias en Navidad o en otras festividades" (Dicc. de la Real Academia). 
Dado su carácter alegre y celebratorio, el villancico fue muy utilizado en la Nueva España para las fiestas durante los dos primeros siglos del Virreinato. Existen textos en español, en náhuatl y en latín que fueron compuestos tanto por los misioneros como por los estudiantes indígenas que estudiaron en las escuelas fundadas por los sacerdotes como San José de los Naturales y Santiago Tlatelolco. Los villancicos son pues uno de los primeros textos frutos del mestizaje cultural. ${ }^{5}$

La forma poética utilizada por los misioneros no era la composición medieval, sino aquella que ya había sido regularizada por los autores cultos; pero que preservaba su parte más apegada a lo tradicional o de hecho netamente tradicional en el estribillo.

El villancico que llegó a suelo americano se conforma de una cabeza o estribillo (de tres o cuatro versos) y varias coplas o pies que desarrollan el tema del estribillo inicial. A su vez cada estrofa se divide en dos partes. La primera se llama mudanza porque cambia de rimas en cada estrofa; en tanto que la segunda se llama vuelta pues la rima es igual a la del estribillo inicial. Después de la vuelta generalmente se repiten los dos últimos versos de la cabeza. ${ }^{6}$

La autoría no era considerada como un problema dado que las composiciones tienen "mucho de arte colectivo" en este tipo de poesía. ${ }^{7}$ Los textos se realizaban para fiestas específicas

${ }^{5}$ Véase el estudio sobre el villancico virreinal de Estrada Jasso 1991.

${ }^{6}$ Cf. Estrada-Jasso 1991: pp. 43-55. Cuando los conquistadores y los misioneros llegan a América traen consigo su cultura popular en las canciones, proverbios y romances. No obstante, los misioneros fueron quienes difundieron de un modo masivo algunos tipos de cantares populares peninsulares a través del teatro de evangelización y el canto, al menos durante los dos primeros siglos del virreinato.

Generalmente "Una melodía conocida, asociada por la gente con un determinado poema de amor, por ejemplo, servía de vehículo ideal para la transmisión del mensaje religioso. Si además se usaba el texto del poema el efecto era doble" (Frenk 1989: p. 60).

${ }^{7}$ En términos generales, el problema de las atribuciones no es de gran impor- 
y, a lo más, se distribuían impresos en hojas sueltas; dicho de otro modo, era un género de ocasión y por lo tanto efímero.

Los misioneros franciscanos fueron los primeros que utilizaron el método musical para la evangelización. Entre los fundadores se encuentran: Pedro de Gante, cuyos esfuerzos culminaron en la fundación del Colegio San José de los naturales en Texcoco - la primera escuela fundada en América (Stevenson 1968: p. 156)-, Amaldo Basaccio y Juan Caro. El éxito fue tal que otras órdenes copiaron las técnicas del franciscano durante varias décadas. Como resultado, las iglesias se llenaron de músicos indígenas quienes eran aventajados estudiantes del canto y la composición. La reacción no tardó en llegar. Durante el Concilio Provincial Mexicano I, de 1555, se emiten documentos en los que se critica el exceso de cantores e instrumentalistas en las iglesias. ${ }^{8}$

El teatro también fue aprovechado por los misioneros para lograr su objetivo de evangelización. La mayoría de las representaciones fueron compuestas para los días de fiestas - numerosos en verdad - tanto profanas como religiosas. Sin embargo "es evidente que [...] ni el teatro profano ni el religioso, en España y en las colonias, tenían "dignidad" suficiente como para que, en términos generales, valiera la pena y fuera costeable publicar sus textos" (Frenk 1989: p. 43).

De ahí que, aunque sabemos que se escribieron más de 200 textos, solamente en el período comprendido entre 1524 y 1600 , pocos, muy pocos registros quedan de ellos. A través de estos últimos y de las crónicas sabemos que la mayoría de los villancicos se compusieron para las representaciones. Generalmente

tancia, porque esta poesía, como casi toda la de la época, tiene mucho de arte colectivo (Frenk 1989: p. 50).

${ }^{8}$ El apogeo musical también se vio representado en la enorme cantidad de libros, mayormente religiosos, que se imprimieron en México durante el siglo xvi y que de acuerdo al cálculo de Stevenson fueron aproximadamente 220. (1968: p. 173). Ricard calcula que entre 1524 y 1572 se imprimieron 109 libros en lenguas indígenas (1986: pp. 122-123). 
se ponían al final de la obra para darle un final feliz, siguiendo la tradición peninsular.

El importante papel que desarrolló la música como lenguaje de contacto entre las culturas que convivían en esas primeras décadas del siglo xvi queda también expresado en los relatos sobre las fiestas tanto litúrgicas como oficiales del virreinato. Un ejemplo de ello es la narración hecha por un fraile anónimo y recogida por Fray Toribio de Benavente (Motolinía), donde se describe la celebración de la fiesta de los cófrades de Nuestra Señora de la Encarnación, celebrada el 16 de abril de 1539. El villancico se cantó en el Auto La caída de nuestros padres y la narración termina:

se fueron cantando por desecha en canto de órgano un villancico que decía:
¿Para qué comió
la primer casada
para qué comió
la fruta vedada?
La primer casada, ella y su marido
a Dios han traído
en pobre posada, por haber comido la fruta vedada. ${ }^{9}$

La estructura es típica del villancico del siglo xvi. Una cabe- za de cuatro versos. Una copla de cuatro versos (mudanza) y la repetición de los dos últimos versos de la cabeza (vuelta). El estilo paralelístico y repetitivo traslucen su origen popular.

Otro texto, esta vez un estribillo del villancico, ocurre en la danza final del "Desposorio Espiritual entre el Pastor Pedro (el Arzobispo Moya de Contreras) y la Iglesia Mejicana", que se

9 Véase también sobre este villancico Méndez Plancarte 1952: p. xxx y Frenk 1987: núm. 1393B, y alli mismo la sección FUENTES. 
considera como "la primera producción teatral de ingenio criollo". Los rasgos populares del estribillo o cabeza de villancico son notorios: ${ }^{10}$

\author{
Pues Menga tiene tal gala \\ y su Esposo gracias mil \\ ¡Viva la bella Zagala \\ para zagal tan gentil!
}

La versión a lo divino incluye a Menga, típico personaje femenino de los estribillos populares, construidos en forma de una gala. Estos cantarcillos sirven para diferentes fiestas -bodas, procesiones- $y$, generalmente, aparece en el texto la palabra identificadora del género. Por ejemplo: ¡Viva la gala y viva el amor, / y viva la causa del vencedor! (C 1224). Su origen se asocia a la fiesta de La Maya, una fiesta dedicada a la fertilidad, y posteriormente se asociaron a los cantares de bodas. ${ }^{11}$ En España, existe un versión profana cuya similitud con el estribillo novohispano es innegable, tanto en las rimas como en la estructura:
Soy hermosa y agraciada, tengo gracias más de mil, llámanme Gira Giralda hija de Giraldo Gil. ${ }^{12}$

. Los ejemplos precedentes son muestras de cómo en el siglo XVI en la Nueva España la lírica popular peninsular penetra de forma masiva, gracias al interés de evangelizar a los indios a

10 Véanse Solórzano 1993: p. 52 y Méndez Plancarte 1952: p. xxxi.

"Sobre la fiesta de La Maya véase a González Palencia 1944 y Caro Baroja 1979. En cuanto a las galas asociadas a las bodas, véase Covarrubias s.v. Halagala y Epithalamio. Son muy interesante las asociaciones entre las galas antiguas y modernas que hace Martínez-Torner 1966: núm. 6.

12 Frenk 1987: núm. 123. 
través de las composiciones religiosas que se cantaban en las fiestas. ${ }^{13}$ No olvidemos que fueron éstas, dado su carácter inclusivo, el principal crisol donde se fundieron las expresiones literarias populares de las diferentes culturas.

El siglo XVII es el siglo del esplendor del villancico. ${ }^{14}$ Entre el segundo tercio del seiscientos y mediados del setecientos se llamaron villancicos a aquellos textos que "exclusivamente se intercalaban en los maitines de las varias fiestas litúrgicas" (Méndez Plancarte 1952: p. xiii). Isabel Pope describe los rasgos distintivos del villancico:

The seventeenth-century villancico put on pious garb and went to church.[...] Chapelmasters in all the important cathedrals composed villancicos which were interpolated into the Office and Mass at high festivals. Taking hints from the style of the Baroque cantata, these church villancico vary in texture from accompanied solos, duets, and trios to six-and twelve- voice choirs. The accompaniment, at first organ or organ and viols, was later in the century enlarged to organ with winds or winds and strings. The ground plan -with like-named components now usually much longer than was the rule in sixteenth century villancicos called for a through-composed estribillo= refrain (solo, duet, or trio, followed by choral responsión= reply); next rapid-five strophic copla[s]=verse[s] (solo) enclosed in double bar; then back to the estribillo [or reponsión] for a repeat of the cycle. (Isabel Pope, MGG, XIII, 1631 apud Stevenson 1976: 3$)^{15}$

${ }^{13} \mathrm{La}$ vuelta a lo divino de un texto popular es muy significativa pues sirve para demostrar que fue muy difundido (Cf. Pedrosa 1992: p. 43). La popularidad de la lírica religiosa ha sido estudiada por Bruce W. Wardropper (1958: p. 153).

14 Véase para la forma del villancico Stevenson 1968: p. 203. En cuanto a las letras, el Maestro de Capilla tenía 83 días al año para que buscara textos de calidad. Un ejemplo de ello fue la Catedral de México, donde comenzó esta costumbre desde 1591. Sin embargo, a decir de los expertos, el texto del villancico llega a su máximo apogeo en México con Sor Juana Inés de la Cruz (Stevenson 1976: p. 4).

${ }^{15}$ A continuación presento la traducción del texto de Pope:

"El villancico del siglo xvir se puso su vestimenta piadosa y se fue a la iglesia. Los Maestros de Capilla en todas las catedrales importantes componían villancicos que eran interpuestos entre el Oficio y la Misa en los grandes festivales. To- 
El espíritu novohispano lo domina todo y se imprime en los villancicos, donde especialmente se realzan características étnicas propias (cfr. Méndez Plancarte 1952, p. viii). La alegría de éstos tuvo como consecuencias el rechazo de las altas autoridades eclesiásticas:

Los villancicos cantados en dialectos son un abuso mucho peor. Los que ahora están de moda mezclan el castellano, portugués, vasco y gallego en una desmedida mescolanza. Es más, características que pertenecen a los negros, moros y otros igualmente hostiles a la religión cristiana, se introducen exclusivamente con intención de divertir de producir risa y de convertir la casa de Dios en un teatro. ${ }^{16}$

Para ilustrar el auge de este tipo de villancicos en el primer período del siglo xVII utilizamos el cancionero del portugués Gaspar Fernández, maestro de capilla de la catedral de Puebla de 1606 hasta su muerte en 1629.

Este manuscrito ha sido considerado como el cancionero más viejo que se conserva en América latina y el más importante en cuanto a la cantidad de textos seculares, donde se preservan villancicos y romances en diferentes lenguas: la mexicana (náhuatl), castellana, portugués, guineo, vizcaíno y negrillo. ${ }^{17}$

mando rasgos del estilo de la cantata barroca, estos villancicos de iglesia varían en textura desde solos acompañados, duetos, y tríos, hasta coros de seis y doce voces. El acompañamiento con órgano ỳ órgano con violas fue. ampliado, más tarde en el siglo, a órganos y vientos o vientos y cuerdas. El plan básico con los mencionados componentes era mucho más largo que lo que fue la norma en los villancicos del siglo xvI, ya que requiere para su composición: un estribillo-refrán (solo, dueto, o trío, seguido por una responsion del coro=respuesta); seguidas por las cinco rápidas estrofas coplas=versos (solo) encerradas entre dobles barras; después vuelta al estribillo o responsión para una repetición del ciclo.

${ }^{16}$ Cita tomada de Yncovenientes, y gravisimos daños que se siguen de que las religiones tengan música de canto de Organo apud Stevenson 1993: p. 393, n. 37.

${ }^{17}$ En este momento estamos estudiando y transcribiendo los textos populares del Cancionero de Gaspar Fernández el cual será editado pronto por Margit Frenk y Pilar Morales. La mala condición del manuscrito debido a una inundación no permite la consulta directa, sin embargo se ha podido acceder al microfilm. 
En el Cancionero de Gaspar Fernández se ilustra la heterogeneidad cultural novohispana no sólo desde el aspecto de las culturas marginadas, como la negra y la indígena, sino también de los europeos que llegaron al Nuevo Mundo.

Los villancicos en portugués y vizcaíno, tanto como los villancicos llamados "de negro", ya eran un género muy recurrido por el teatro español del siglo anterior y su función era eminentemente cómica. De manera que, quizás debido a su éxito peninsular, son reutilizados en la Nueva España.

Todos los textos pertenecen al manuscrito de Gaspar Fernández cuyas composiciones comprenden el período 1609-1616. Solo citaré tres villancicos donde se oyen tres voces representativas de las castas marginadas de la Nueva España: el primero en náhuatl, el segundo en mestizo y el tercero en negrillo:

Xicochi conetzintle
coamis huihui joco
in agelos me
aleloya, aleloya

(GF: 219v-220r) ${ }^{18}$

Tios mío, mi goraçon, mo pan pani pachi nigual amo xichoco abiçion $\mathrm{q}$ <ue> lloraréis el maçegual.

(GF: $101 \mathrm{v}-102)^{19}$

Gurumbé, gurumbé, ma si qui cansame, que preso hatame desi pane qui dame,

${ }^{18}$ La traducción del villancico según Patrick Johansson sería "Duérmete, niñito,J pues vinieron a mecerte /os ángeles / aleluya, aleluya".

${ }^{19} \mathrm{La}$ traducción del villancico según Patrick Johansson sería: "Dios mío, mi corazón, / por ti yo me alegro; / no llores, mi afición, / lloraréis al macehual”. 
q<ue $>$ traji pañoli di Santo Tomé.

Gurumbé, gurumbé

a negrito de cucurumbé

(GF: $118 \mathrm{v}-119 \mathrm{r})^{20}$

Las diferencias de las voces en los textos es notoria. Mientras que en los dos primeros villancicos —en náhuatl, una canción de cuna vuelta a lo divino y en mestizo, dedicado al nacimiento de Dios - no se aprecia una intención cómica, ni se ha ce referencia a ninguna situación extraliteraria; en el villancico de negro existiría un tono más lúdico. De hecho existe una velada burla a la glotonería del personaje, quien piensa "hartarse" con el "pan que dan"; pan, que no es otra cosa que la Eucaristía. Quizás la intención cómica del bilingüismo permitía que a través de la relajación de la fiesta la gente se sintiera identificada e incluida (Bajtín 1995: p. 79).

Sabemos que los anteriores textos fueron compuestos para ocasiones especiales. A pesar de estar en un cuaderno de trabajo de un culto Maestro de Capilla portugués, el lirismo de los villancicos comparado con algunos registros anteriores muestra, como he mencionado en otra parte, un rompimiento del entramado poético que contiene al náhuatl y deja entrever parte de la palabra indígena. En cuanto a los villancico de negro de este cancionero, Margit Frenk ha resaltado su originalidad frente a otros del mismo género. ${ }^{21}$

20 Para el tema de los "villancicos de Negro" véase la tesis doctoral de Glenn Swiadonn donde se estudia el género tanto en autores españoles como americanos; en el trabajo, entre otras disquisiciones, Swiadon explica los orígenes de los vocablos africanos que aparecen en las composiciones. Por ejemplo el término gurumbe "designa a un tipo de música bailable de origen africano. Además, por su fonética, gurumbé se relaciona con gwomba ('batir las manos') y con la raíz ngoma ('tambor') (Swiadon 2000: p. 91).

21 Margit Frenk, "Los cantos religiosos de negros a comienzo del siglo xvII novohispano" ponencia en el Congreso Folclor Literario en México, organizado por el Centro de Estudios de las Tradiciones de El Colegio de Michoacán, 25 de abril de 2001. 


\section{El chuchumbé}

En el siglo XVIII comienza el rechazo por los villancicos sobre todo por la élite letrada pues "ya comienza a resquebrajarse la compenetración que - al menos ante Dios- unificaba a todas las clases sociales y culturales en un sólo "pueblo cristiano" (Méndez Plancarte 1952, LIv). Parecería que todo el ímpetu del siglo anterior es visto desde la nueva perspectiva del siglo xviII. Las espontáneas letras de antes ahora se consideran chabacanas y vulgares. $^{22}$

De este modo la gente culta da la espalda a la cultura popular que vuelve a su cauce natural: la oralidad y las hojas impresas. Asimismo, la interacción entre las diversas culturas se ha profundizado más. El peligro de las herejías ha pasado y se hace más hincapié en la moral cristiana. Se condena la aparición de bailes eróticos, sobre todo en ciudades y puertos, que eran bailados y cantados por las castas marginadas; además, algunas de estas danzas fueron perseguidas por la Inquisición. Se conserva el texto de un son conocido como "El Chuchumbe" que, de hecho, tiene diferentes grupos de coplas. Para este estudio he elegido una de las versiones que está en el libro de Baudot-Méndez. Aquí sólo mostraré algunas de las coplas que fueron condenadas por el Santo Oficio, en $1766 .{ }^{23}$ Asimismo, en otro artículo estudian este son donde explican que existían varias versiones del mismo, algunas eróticas y otras políticas, además señalan los estudiosos la posibilidad de que este son haya sido una reelaboración del pueblo: ${ }^{24}$

22 Uno de los ejemplos son las opiniones de Feijoo quien cuando habla de poesía dice que "la peor es la que se oye en Cantinelas Sagradas" donde "toda la gracia consiste en equívocos bajos, metáforas triviales, retruécanos pueriles", en el Discurso en la Música en los Templos apud Méndez Plancarte 1952: pp. Liv y LIV-LIX.

${ }^{23}$ Difiero en un aspecto mencionado por Robles Cahero sobre "El chuchumbé", sobre todo en designar a la estructura popular como "defectuosa", pues me parece más acertado el término de irregular.

${ }^{24}$ Cf. Baudot y Méndez 1987. 
En la esquina está parado

un fraile de la Merced, con los hábitos alzados

enseñando el chuchumbé.

Que te pongas bien, que te pongas mal, el chuchumbé te he de soplar.

Esta vieja santularia que va y viene a San Francisco, toma el Padre, daca el Padre, y es el padre de sus hijos.

De mi chuchumbé, de mi cundabal, que te pongas bien, que te voy a aviar.

El demonio de la China del barrio de la Merced, y cómo se zarandeaba metiéndole el chuchumbé.

Que te pongas bien, que te pongas mal, el chuchumbé te he de soplar.

Eres Marta la piadosa en cuanto a tu caridad, que no llega peregrino que socorrido no va.

Si vuestra merced quisiera, yo le mandara 
el cachibache

de verinduaga.

En la esquina hay puñaladas, ¡Ay, dios! ¿qué será de mí?

Que aquellos tontos se matan por esto que tengo aquí.

Si vuestra merced no quiere venir conmigo

Señor Villalba

le dará el castigo.

$Y$ si no vienes

de buena gana, Villalba

te dará el premio.

Me casé con un soldado, lo hicieron cabo de escuadra, y todas las noches quiere su merced montar la guardia.

Sabe vuestra merced que, sabe vuestra merced que, "Canta la Misa" le han puesto a vuestra merced.

Mi marido se fue al puerto por hacer burla de mí, él de fuerza ha de volver por lo que dejó aquí.

Que te pongas bien, que te pongas mal, con mi chuchumbé te he de aviar. 
Y si no te aviare, yo te aviaré con lo que le cuelga a mi chuchumbé.

¿Qué te puede dar un fraile por mucho amor que te tenga? un polvito de tabaco y un responso cuando mueras.

El chuchumbé de las doncellas ellas conmigo y yo con ellas.

En la esquina está parado el que me mantiene a mí el que me paga la casa y el que me da de vestir.

Y para alivio de las casadas, vivir en cueros y amancebadas.

Estaba la muerte en cueros sentada en un escritorio, y su madre le decía: ¿no tienes frío, Demonio?

Vente conmigo, vente conmigo, que soy soldado de los amarillos.

Por aquí pasó la muerte con su aguja y su dedal, 
preguntando de casa en casa, ¿hay trapos que remendar?

Sabe vuestra merced que, sabe vuestra merced que, "la Puta en Cuaresma" le han puesto a vuestra merced.

Por aquí pasó la muerte poniéndome mala cara, y yo cantando le dije: “¡no te apures, alcaparra!”.

Si vuestra merced quisiera, y no se enojara, "Carga la jaula" se le quedara.

Estaba la Muerte en cueros sentada en un taburete, en un lado estaba el pulque $y$ en el otro el aguardiente.

Sabe vuestra merced que, sabe vuestra merced que, que me meto a gringo y me llevo a vuestra merced.

(Baudot-Méndez 1997: 36)

Este son fue perseguido durante más de cuarenta años por la Inquisición, como se observa en los procesos donde existen prohibiciones sistemáticas desde 1766 hasta 1802. Asimismo "El chuchumbê" incluyó coplas políticas y satíricas. ${ }^{25}$ Entre otras acusaciones, se describe al baile como "con ademanes,

25 Debido a la limitación de espacio no he incluido la versión completa del Chuchumbé; véase para mayor información sobre el tema Baudot- Méndez 1997: pp. 28-41. 
meneos, zarandeos, contrarios todos a la honestidad y mal ejemplo de los que lo ven como asistentes, por mezclarse en él manoseos de tramo en tramo, abrazos y dar barriga con barriga (vol. 1095, fol. 298r). ${ }^{26}$

En el texto de "El Chuchumbé se registra la multiplicidad cultural novohispana. Primero, la influencia africana se puede observar tanto en la forma como en el contenido. La combinación de cuartetas octosilábicas y pentasilábicas son comunes en "las danzas y música de los negros, perpetuada en las Antillas y en las costas mexicanas". ${ }^{27}$ En la letra misma está la cultura africana, ya que el nombre del son puede derivar del vocablo de origen africano cumbé que significa 'ombligo'.

Segundo, también se incluye la visión mestiza en la penúltima copla. Por un lado, la mención de la "Muerte en cueros", que expresa ese trato satírico de la muerte netamente mestizo; por otro lado, las menciones de las bebidas embriagantes como son el pulque —que es una bebida mexicana prehispánica consumida por el pueblo- y el aguardiente. ${ }^{28}$

Tercero, la presencia de la cultura dominante española se manifiesta en la lengua utilizada en la canción. Sin embargo, la rebelión contra el lenguaje impuesto, la transgresión a lo establecido se hace mediante la sátira erótica que es justamente lo censurado.

${ }^{26} \mathrm{El}$ baile se propagó junto con "los llamados rosarios y vestidos a la moda diablesca", traídos de La Habana por algunos individuos que por no tener recursos se estacionaron en Veracruz (cf. Aguirre Tinoco 1983: pp. 14-16).

${ }^{27}$ Gabriel Saldívar, Historia de la música, México, Libros de México (1934) 1981 , p. 227 (Biblioteca Enciclopédica del Estado de México) apud BaudotMéndez 1997: n. 4, p. 33.

${ }^{28}$ De acuerdo con Santamaría, el pulque "es una bebida embriagante, espirituosa, blanca y espesa, de aspecto nauseabundo y sabor desagradable, que se obtiene haciendo fermentar el aguamiel o jugo que dan los bohordos del maguey cortados antes de florecer. Es la bebida peculiar de la gente pobre en la Mesa Central, para la cual constituye un factor principal de alimentación con el chile y la tortilla (1959, s.v. pulque). El pulque y las pulquerías representan una de los aspectos de aculturación más interesantes de analizar. 
La mención del gringo en la última estrofa recuerda la presencia de los que poseen la "lengua distinta". ${ }^{29} \mathrm{La}$ expresión sin embargo no queda clara. ¿Será una amenaza o una invitación? Hay que tomar en cuenta que se cree que este son se desarrolló originariamente en Veracruz, puerto destacado, donde era común el intercambio entre diferentes culturas. De acuerdo con García de León:

Se mezclan en ella los elementos indígenas preexistentes (la civilización de los nahuas costeños, totonacas y popolucas: una civilización de tolerancia sensual y representada todavía en la "magia de la risa" de las terracotas de Remojadas), los rasgos - algunos muy afines en los cultos y el ritual- venidos del occidente de África (el culto a la ceiba, etc.), la cultura popular de Andalucía, Portugal y las Canarias y repetidas interinfluencias con Caracas-Maracaibo y la Nueva Andalucía (1994: p. 26).

La influencia de la cultura africana no sólo repercutió en los indianos y en los peninsulares, como queda visto en el proceso de la Inquisición donde se describe a las acusadas como "españolas y muchachas, distraídas de ropa". El conocimiento de que los consumidores y escuchas de esta poesía popular no solamente eran de las culturas marginales muestra cómo existía, paralela a la cultura letrada, una cultura común a las diferentes castas que pertenecía a la plaza y a los mercados: en otras palabras, una cultura popular.

Asimismo, en cuanto a la estructura, mencionaremos la utilización recurrente de figuras de repetición como el paralelismo que son típicas de la poesía popular moderna: "Sabe vuestra merced que", "Vente conmigo". Se puede agregar como rasgo popular la utilización de expresiones que se han convertido en

${ }^{29}$ Cf. Baudot -Méndez 1997: p. 37. La voz gringo deriva de griego, con lo que se denominaba en España a una 'lengua incomprensible'. En los siglos Xvill-xIX se confunde la voz griego por gringo (Corominas 1955-57, s.v. griego). 
fórmulas como: "Estaba la Muerte en". Además la diversidad de metros, de temas y de voces le dan un tono muy vivaz y burlón. Un ejemplo son las estrofas de voz femenina que comienzan "Me casé con un soldado" y "Mi marido se fue al puerto", donde se destaca una sexualidad desbordante y descarada.

La continuidad de lo popular en la tradición oral se comprueba en la supervivencia de textos. Si seguimos el hilo conductor de "El Chuchumbé", nos encontramos en pleno siglo xx una copla que estrecha los siglos entre el son perseguido por la Inquisición y un juego infantil.

Esa copla, como materia tradicional, ha sido adaptada a las nuevas realidades por ello se puede afirmar que es una supervivencia parcial de aquella incluida en el baile dieciochesco. El juego de niños al que me refiero se llama: "Estaba la muerte sentada". Sus "coplas las utilizan los muchachos para divertirse satirizándose entre sí; al son de ellas brincan y giran alrededor de aquél que consideran la Media Muerte, al que le tiran de la ropa, le tocan con varitas o simplemente bailan alrededor de él" (Mendoza 1951: pp. 84-85, núm. 91):

\author{
Estaba la Media Muerte \\ sentada en un taburete \\ los muchachos de traviesos \\ le quitaron el bonete. ${ }^{30}$
}

Lo anterior muestra que dentro de la misma tradición oral los textos a veces pierden su funcionalidad inicial, pero el texto se adapta a las nuevas circunstancias y se conserva, siempre y cuando haya pasado por la censura de la comunidad.

${ }^{30} \mathrm{La}$ copla fue comunicada a Vicente T. Mendoza por el señor Mariano Argote, de 60 años, en la ciudad de México, en noviembre de 1939, y proviene de San Gabriel Guzmán, Jalisco (Mendoza 1951: p. 201). Véase también Frenk 19751985: III, núm. 3796. La copla se relaciona con otro juego titulado "Estaba la Muerte un día" también recopilado por Mendoza 1951: 85, núm. 92. 
A pesar de ser escasos los textos registrados por escrito podemos trazar algunas líneas entre ellos que representan las tendencias que pudo seguir la lírica de plaza. El encuentro entre lo peninsular y lo americano desde la perspectiva popular tuvo diversas fases.

Los comienzos o antecedentes están representados por el género de los villancicos, expresión que perteneció al discurso de la cultura elitista y que fueron muy difundidos en el Nuevo Mundo; se trata de textos donde se incluían las lenguas de mayor difusión, tanto dominantes como dominadas, unidas por el espíritu de la iglesia de homogeneizar culturas y clases en una sola religión. A pesar de lo anterior algunos rasgos poéticos propios novohispanos se escapan del rigor de la forma, permitiendo entrever una sensibilidad poética distinta.

Más tarde, los diferentes contactos entre culturas marginales comienzan a propagarse y conforman una lírica popular secular propia, fuera de la oficialidad, donde se recupera lo carnavalesco. El erotismo y la burla anticlerical lo permean todo. Las formas se diversifican y los metros son irregulares. Y es ésta lírica, la originada en el siglo XVIII, la que se preserva hasta nuestros días.

El puente entre unos textos y otros aún no está terminado dada la escasez de registros; sin embargo, el presente trabajo pretende animar a los estudiosos a seguir construyéndolo.

\section{Bibliografía}

AguiRre Tinoco, Humberto, Sones de la tierra y cantares jarochos, Secretaría de Educación Pública, Dirección General de Culturas Populares, México, Premiá, 1983.

BaudoT, George y María Águeda MénDEZ, “' 'El chuchumbe', un son jacarandoso virreinal”, Caravelle, 48, 1987, pp. 163-171. 
Amores prohibidos: la palabra condenada en el México de los virreyes (Antología de coplas y versos censurados por la Inquisición en México), prol. Elías Trabulse, México, Siglo XXI, 1997.

BAJTín, Mijaíl, La Cultura popular en la Edad Media y en el Renacimiento. El contexto de Francois Rabelais, Madrid, Alianza, 1995 (Alianza Universidad, 493).

Cancionero de Gaspar Fernández, Manuscrito, Archivo Musical del Archivo Histórico de la Catedral de Oaxaca.

Caro Baroja, Julio, La estación del amor: fiestas populares de mayo a San Juan, Madrid, Taurus, 1979.

Corominas, Joan, Diccionario crítico etimológico de la lengua castellana, Madrid, Gredos, 1955-1957.

Covarrubias, Sebastián de, 1611, Tesoro de la lengua castellana, ed. Martín de Riquer, Barcelona, Horta, 1943.

Estrada-Jasso, Andrés, El villancico virreinal, 1. Siglo xvI. Villancicos, canciones y ensaladas, San Luis Potosí, Archivo Histórico del Estado de San Luis Potosí, 1991, 3 vv.

FRENK, Margit, "Entre folklore y literatura", Jornadas 64, México, El Colegio de México, 1971.

- Corpus de la antigua lírica popular hispánica (siglos XV a xvII), Madrid, Castalia, 1987 (Nueva Biblioteca de Erudición y Crítica, 1).

—, et al., Cancionero Folklórico de México, México, El Colegio de México, 1975-1985, 5 vv.

García dE LEón, Antonio, "Contrapunto entre lo barroco y lo popular en el Veracruz colonial”, Heterofonía, 109, 1994, pp. 17-27.

González de EslaVA, Fernán, 1610, Villancicos, romances, ensala- das y otras canciones devotas (Libro segundo de los coloquios espirituales y sacramentales y Canciones divinas, México, Diego Lopez Davalos), ed. Margit Frenk, México, El Colegio de México, 1989.

González Palencia, Ángel y Eugenio Mele, La maya notas para su estudio en España, Madrid, CSIC, 1944 (Biblioteca de Tradiciones Populares, 7).

MaGis, Carlos H., La lírica popular contemporánea: España, México, Argentina, México, El Colegio de México, 1969. 
MARTÍNEZ TORNER, Eduardo, Lírica hispánica. Relaciones entre lo popular y lo culto, Madrid, Castalia, 1952 (La lupa y el escalpelo, 5). MASERA, Mariana, "Algunos aspectos de la lírica tradicional: los inicios de las coplas", en Memoria: XX aniversario del Seminario de Poética, México, UNAM, 2000, pp. 141-151.

__, "Que non dormiré sola, non". La voz femenina en la antigua lírica hispánica”, Barcelona, Azul, 2001.

Mendoza, Vicente T., La lírica infantil de México, México, Fondo de Cultura Económica (1951) 1994 (Lecturas Mexicanas, 26).

Pedrosa, José Manuel, "La novia exigente: de unas seguidillas del siglo XVII a "ball-rodo" catalán y canción paralelística sefardî", Criticón, 56, 1992, pp. 41-52.

Real Academia Española, Diccionario de la lengua, Madrid, Espasa-Calpe, 1984.

Reyes, Alfonso, Letras de la Nueva España, México Fondo de Cultura Económica, 1992 (Colección Popular, 317).

Robles Cahero, José Antonio, "La memoria del cuerpo y la transmisión cultural: danzas populares en el siglo xvil novohispano", Heterofonía, 2, 1984, pp. 26-43.

SÁnChez Romeralo, Antonio, El villancico: estudios sobre la lírica popular en los siglos xV y XVI, Madrid, Gredos, 1969 (Estudios y Ensayos, II).

Santamaría, Francisco J., Diccionario de mejicanismos, México, Porrúa (1959) 1992.

Solórzano, Carlos, Teatro mexicano, historia y dramaturgia, t. III, Autos, coloquios y entremeses del siglo xvı, México, CONACULTA, 1993.

SOR JUANA INÉS DE LA CRUZ, Obras completas. Villancicos y Letras sacras, vol. II, edn. Alfonso Méndez Plancarte, México, Fondo de Cultura Económica, 1952.

STEVEnSON, Robert, "Sixteenth and Seventeenth Century Resources in Mexico", Fontes Artis Musicae, vol. 1, 1954, pp. 69-78 y vol. 1, 1955, pp. 10-15.

- Spanish Cathedral Music in Golden Age, Berkeley, University of California Press, 1961, reimpr. La música en las catedrales españolas del Siglo de Oro, Madrid, Alianza, 1993. 
—, Music in Aztec \& Inca Territory, Berkeley, University of California Press (1968) 1976.

_- Renaissance and Baroque Musical Sources in the Americas, Washington, D.C., General Secretariat, Organization of American States, 1970.

_- Christmas Music from Baroque Mexico, Berkeley, University of California Press, 1974.

__ La música en las catedrales españolas del Siglo de Oro, Madrid, Alianza, 1993, Spanish Cathedral Music in the Golden Age, Berkeley, University of California Press, 1961.

Swiadon Martínez, Glenn, "Los villancicos de negro en el siglo xviI", Tesis Doctoral, Facultad de Filosofía y Letras, UNAM, 2000.

Tenorio, Martha Lilia, Los villancicos de Sor Juana, México, El Colegio de México, 1999.

W ARDROPPER, Bruce W., Historia de la poesía lírica a lo divino en la Cristiandad occidental, Madrid, Revista de Occidente, 1958. 